
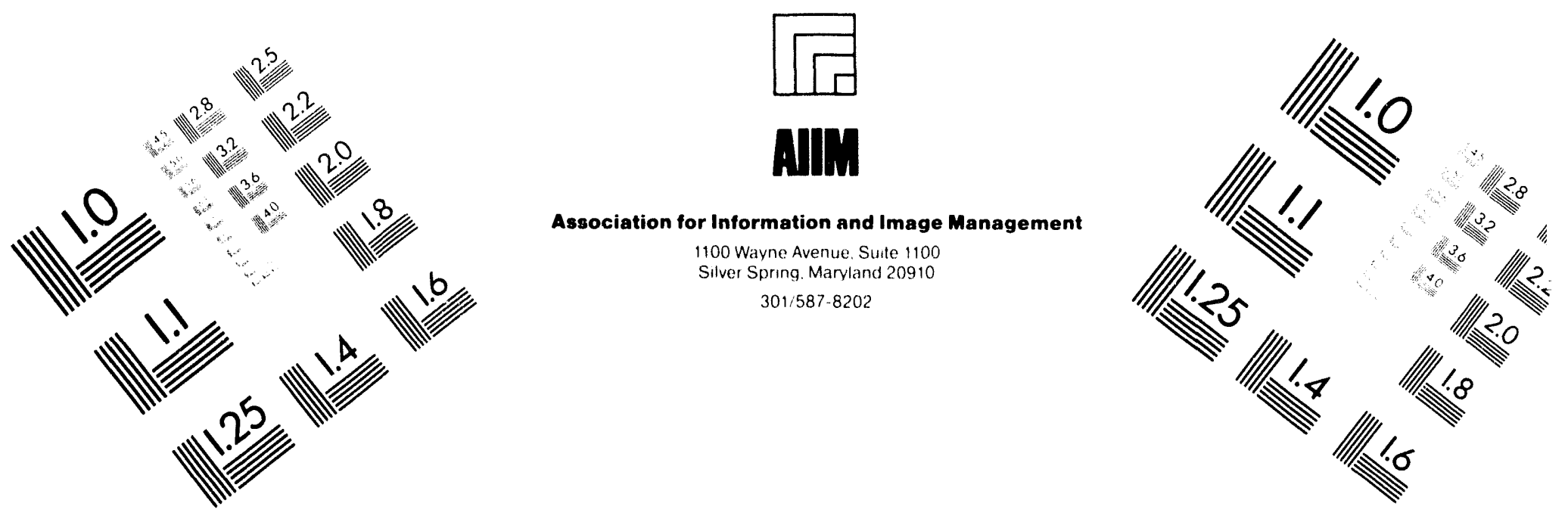

\title{
Centimeter
}

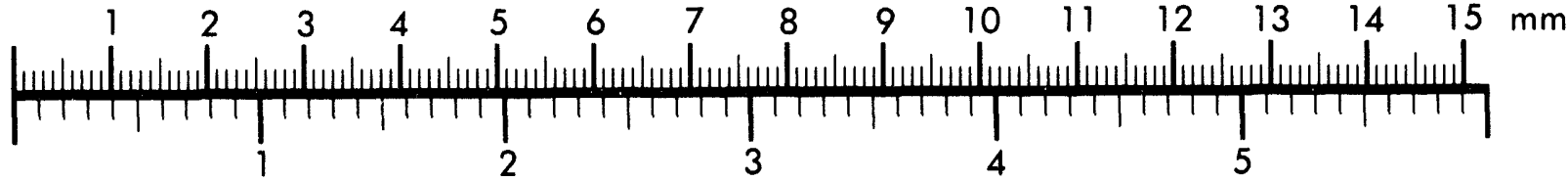
Inches
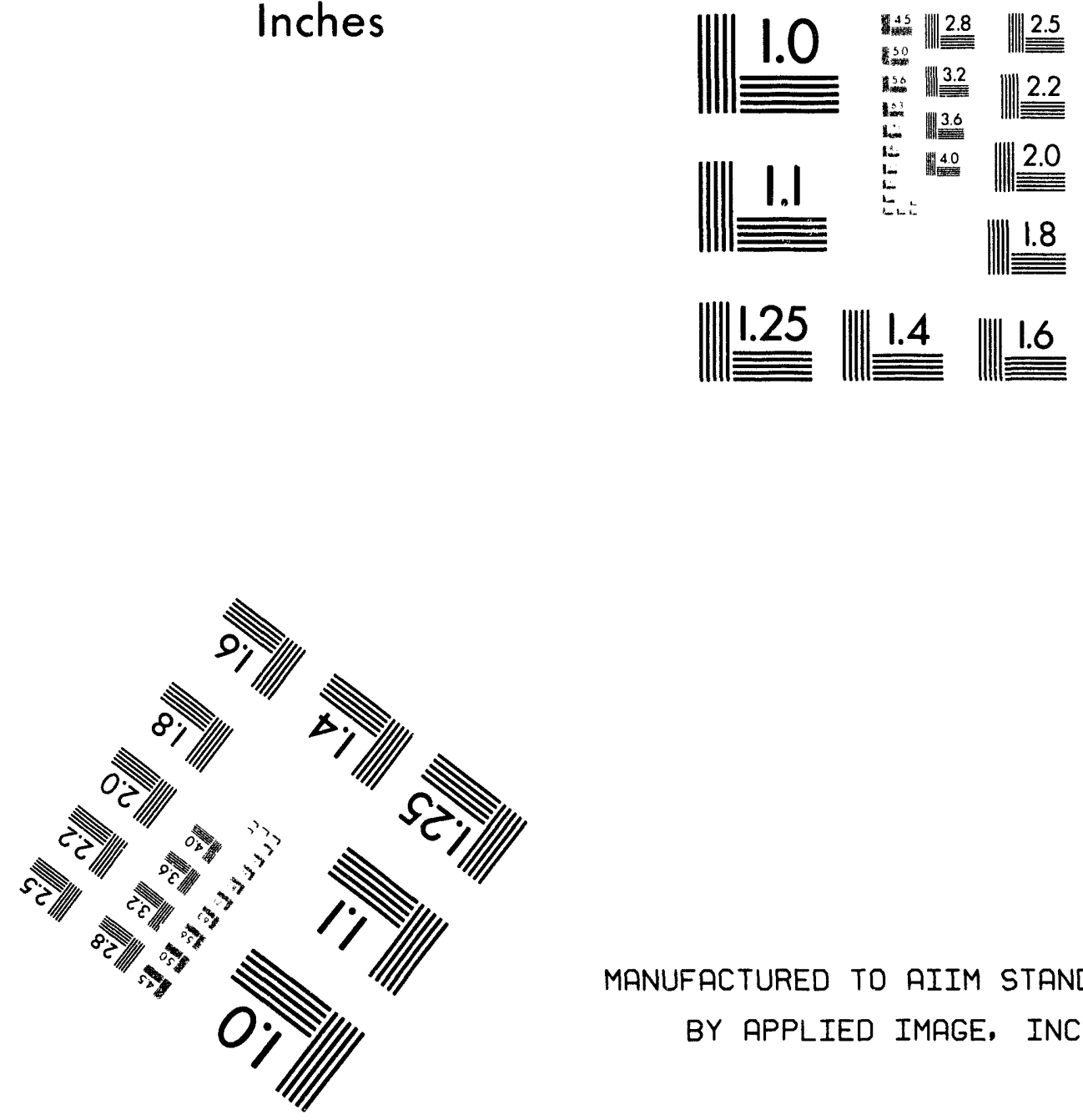

MANUFACTURED TO AIIM STANDARDS

BY APPLIED IMAGE. INC.

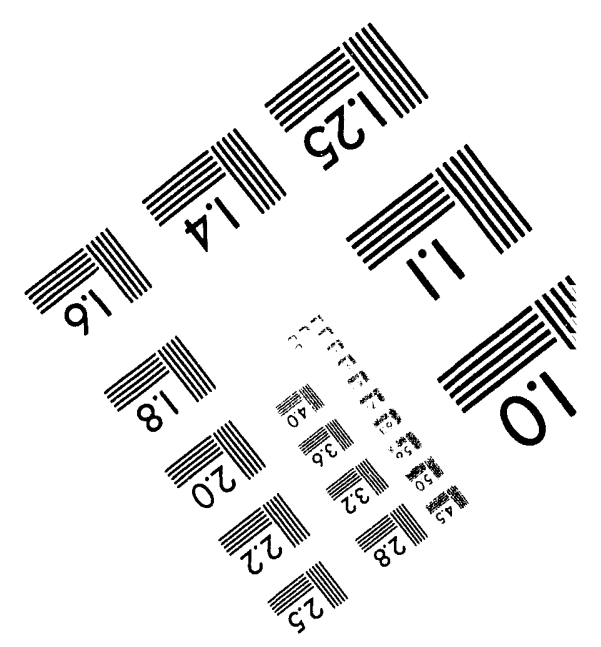



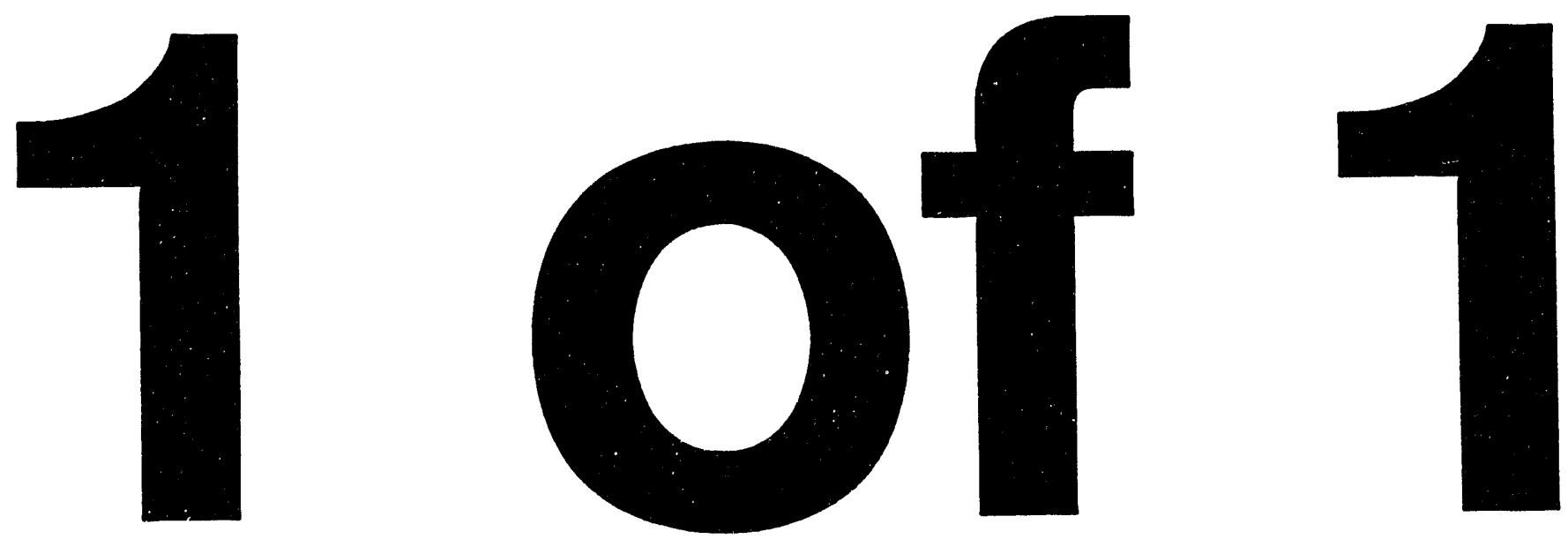


\title{
DISCLAIMER
}

This report was prepared as an account of work sponsored by an agency of the United States Government. Neither the United States Government nor any agency thereof, nor any of their employees, makes any warranty, express or implied, or assumes any legal liability or responsibility for the accuracy, completeness, or usefulness of any information, apparatus, product, or process disclosed, or represents that its use would not infringe privately owned rights. Reference herein to any specific commercial product, process, or service by trade name, trademark, manufacturer, or otheiwise does not necessarily constitute or imply its endorsement, recommendation, or favoring by the United States Government or any agency thereof. The views and opinions of authors expressed herein do not necessarily state or reflect those of the United States Government or any agency thereof.

\section{Positron annihilation studies of defects in molecular beam epitaxy grown III-V layers}

\author{
M.T. Umlor ${ }^{1}$, P.Asoka-Kumar ${ }^{2}$, D.J. Keeble ${ }^{1}$, P.W. Cooke ${ }^{3}$ and K.G Lynn ${ }^{2}$ \\ 1 Deparment of Physics, Michigan Technological University, Houghtom, MI 49931, USA. \\ 2 Department of Physics, Brookhaven National Laboratory, Upton, NY 11973, USA. \\ ${ }^{3}$ GEO-Centers, INC., Fon Monmouth Operation, Earonsown, NJ 07703, USA.
}

Submitted to: The Editor

Applied Surface Science by: D.J. Keeble,

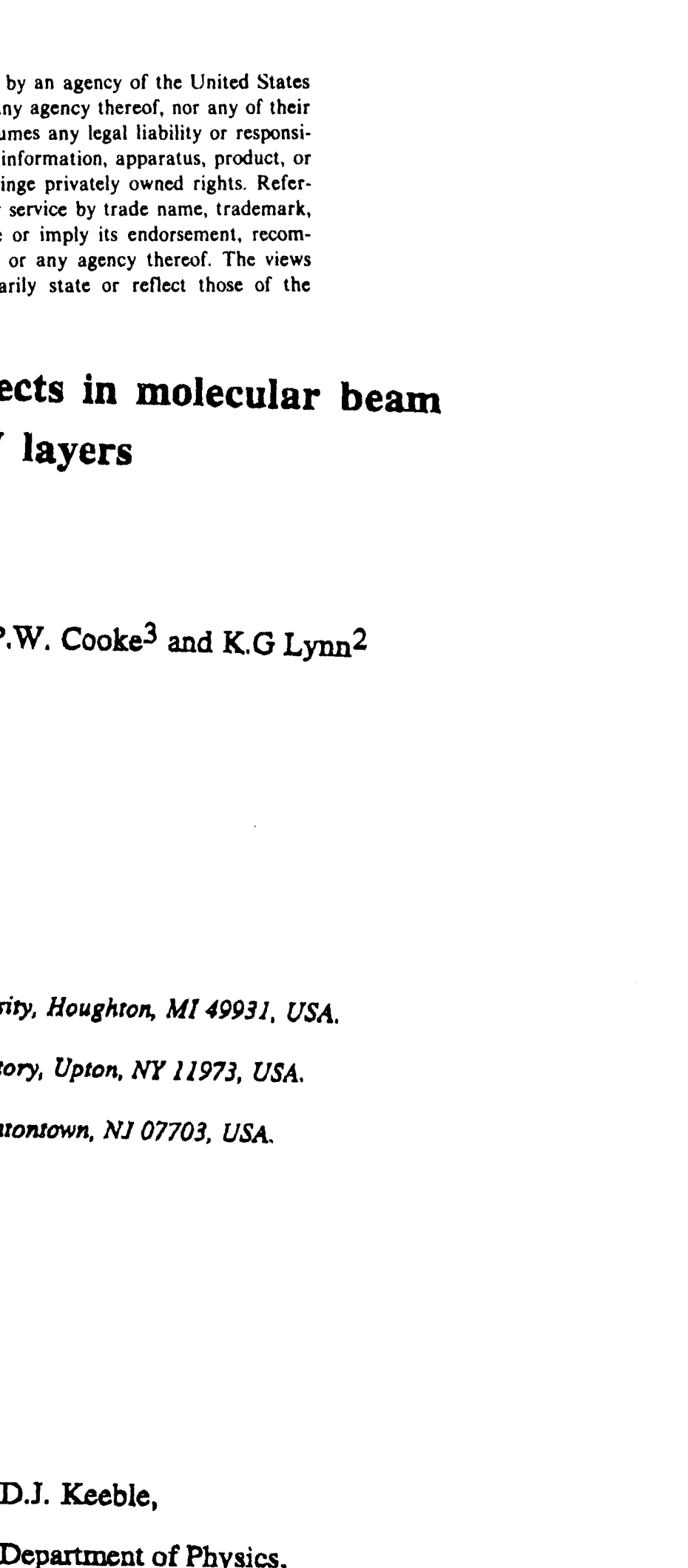

Michigan Technological University, Houghton, MI 49931, USA.

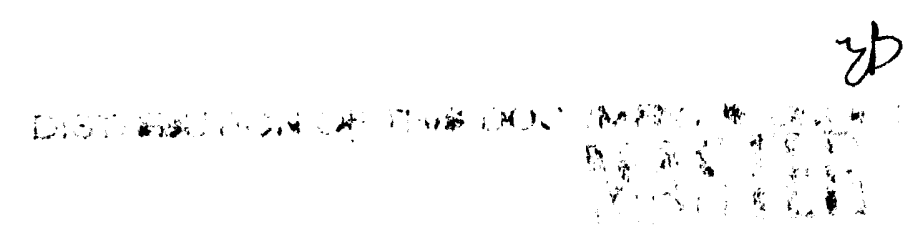




\section{Introduction}

Variable energy positron beam (VEPB) experiments on molecular beam epitaxy (MBE) grown III-V materials are detailed. Vacancy related defects with Si doped AlGaAs and anneal induced vacancy defect formation in MBE GaAs are investigated.

Energetic positrons implanted into a condensed medium quickly thermalize in a few picoseconds and diffuse through the lattice $(-100 \mathrm{~nm}$ in a defect free environment) before subsequent annihilation with an electron producing two nearly anti-collinear $511 \mathrm{keV}$ gamma rays. Due to the finite momentum of the annihilation pair (dominated by the electron momentum) the gamma ray photons are Doppler broadened, thus, the $511 \mathrm{keV}$ line width provides a sensitive probe to changes in the local electronic environment. Open volume defects, due to the absence of the ion core, provide a potential well which can trap positrons into a localized state. In such a localized state the overlap of the positron wavefunction with the high momentum core electrons is reduced, thereby, reducing the Doppler broadening of the $511 \mathrm{keV}$ annihilation photon. The 511 $\mathrm{keV}$ line width of the gamma rays are parameterized using the $S$ parameter defined simply as the number of counts in a central region of the spectrum divided by the total counts in the 511 photopeak. An increase in open volume defects is then observed as an increase in the $S$ parameter.

\section{Experimental}

Samples investigated were prepared in a Varian GEN II MBE system at a growth rate of 1 $\mu \mathrm{m} / \mathrm{hr}$. Samples were grown to a thickness of $2 \mu \mathrm{m}$ on (100) SI-GaAs substrates. The substrates were indium bonded to a wafer holder and a thermocouple utilized to monitor the growth temperature. An ionization gauge at the sample position was used to measure the As and Ga beam flux and a beam equivalent pressure (BEP) calculated. All LT-GaAs samples were grown with an As4 species while the $\mathrm{Al}_{\mathrm{X}} \mathrm{Ga}_{1-\mathrm{X}}$ As samples used the As2 species.

The variable energy positron annihilation experiments used a slow positron beam described elsewhere[21]. The positron implantation energy was varied from 0.5 to $50 \mathrm{keV}$ with approximately $10^{6}$ annihilation events recorded at each energy. The S parameter was defined 
Figure 2 shows the results of measurements before and after infrared irradiation on the doped sample at $25 \mathrm{~K}$. The figure indicates that as the DX center undergoes the metastable transition to the simple donor state, an opon volume defect is romoved from the lattice. This observation is also consistent with an open volume associated with the microstructure of the DX center. The change in $S$ parameter before and after irradiation is $-0.4 \%$ which is smaller than expected for an isolated vacancy in GaAs present in the $10^{18} \mathrm{~cm}^{-3}$ range. This is indicative that the open volume is small than an isolated mono-vacancy. These results are in agreement with thoses of Makinen et al. [20].

\subsection{Low Temperature MBE GaAs}

\subsection{MBE Grown GaAs}

The first report on the properties of the molecular boam epitaxy (MBE) growth of GaAs at substrate temperanures below the normal 580 to $600^{\circ} \mathrm{C}$ range (LT-GaAs) was made by Murotani et al, [1] in 1978. The research included the first use of LT-GaAs as a buffer layer in a GaAs field effect transistor utilizing a $500^{\circ} \mathrm{C}$ growth, however, the material received little interest until 1988 when Smith el al. [2] reported on the use of LT-GaAs grown at $200^{\circ} \mathrm{C}$ and annealed at $600^{\circ} \mathrm{C}$ as a buffer layer to eliminate backgating and light sensitivity. Since the publication of this now famous paper hundreds of reports on the properties and uses of LT-GaAs have appeared in the scientific literature. For a detailed review of the present understanding of the properties and device characteristics of LT-GaAs the reader is referred to ref. $[3,4,5]$.

The as grown LT-GaAs materials show excellent crystalinity up to a critical thickness[6] after which the growing epitaxial layer becomes amorphous. The material, however, is nonstoichiometric with an excess arsenic concentration on the order of $1 \%$ with an expanded lattice parameter and an extremely high conceniration of point dofects[7]. Following a $600^{\circ} \mathrm{C}$ anneal the excess arsenic remains, but, the lattice parameter relaxes back to that of bulk GaAs. Further, arsenic precipitates with diameters in the range 2-10 $\mathrm{nm}$ and concentration of $1 \times 10^{17} \mathrm{~cm}^{-3}$ are observed in the $600^{\circ} \mathrm{C}$ annealed layer[8]. The material also becomes highly resistive $\left(-10^{6} \mathrm{~cm}\right)$, 
of this increase on growth temperature for a series of samples grown with a $B E P=20$. The thermal instability to the formation of open volume defects for samples grown below $450{ }^{\circ} \mathrm{C}$ is directly evident. In general, as the growth temperature is lowered the vacancy related defect concentration in both the as grown and annealed samples increases. The increase in the $S$ parameter was found to be commensurate with the relaxation of the lattice parameter observed by X-ray rocking curve measurements. It is interesting to note that the samples grown at 350 and $450{ }^{\circ} \mathrm{C}$ show no as grown vacancy related defects and both gave a single $\mathrm{X}$-ray rocking curve peak, but, the annealed data on these two samples is quite different. Preliminary results also indicate an increase in vacancy defect concentration with increased BEP at a given growth temperature.

Keeble et al.[12] demonstrated that the dominant positron trapping defect produced during the anneal is physically distinct from the defect present in the as grown material. To investigate this defect formation, isochronal anneals were performed on samples grown at 230 and $350^{\circ} \mathrm{C}$ and are shown in Figure 4. A distinct difference in the materials is clearly seen. First, the increase in $\mathbf{S}$ parameter of the $230^{\circ} \mathrm{C}$ grown sample starts at a lower temperature and reaches a value of 1.035 at $525^{\circ} \mathrm{C}$ which is similar to that reported for divacancies or larger open volume defects[22]. However, the $S$ parameter for the $350^{\circ} \mathrm{C}$ grown sample saturates at about 1.025 which is a typical value for mono-vacancies in GaAs[22]. Second, an increase in the S parameter for anneals above $600^{\circ} \mathrm{C}$ is observed in the $230^{\circ} \mathrm{C}$ grown sample, which is consistent with vacancy cluster formation, while the sample grown at $350^{\circ} \mathrm{C}$ shows no change with anneals from 550 to $700^{\circ} \mathrm{C}$. If one assumes a first order rate equation for the defect formation and a linear dependence of the $S$ parameter on the defect production, than for a series of oqually spaced anneal temperatures of duration (sec) the activation energy for the defect formation can be expressed as[23];

$$
e=k_{B} T_{m} \ln \left[\frac{K_{0} \tau}{\ln \left[\frac{T_{f}-T_{1}}{T_{f}-T_{1}-2 \Delta T}\right]}\right]
$$

where: $k_{B}$ is the Boltzman constant, $K_{0}$ is the vibrational attempt frequency, $T_{i}$ is the starting temperature for the defect production, $T_{f}$ is the final temperature for the defect production, and $T_{m}$ 
vacancy in the As rich limit.

Work supported by the U.S. Dept. of Energy, Division of Materials Sciences under Contract No. DE-ACO2-76CHOOO16 


\section{List of References}

1. T. Murotani, F. Shimanoe, and S Mitsui, J. Crystal Growth 45 (1978) 302

2. F.W. Smith, A.R. Calawa, C.L. Chen, M.J. Manfra, and L.J. Mahoney, IEEE Electron Device Lett._9 (1988) 77

3. G.L. Witt, A.R. Calawa, U. Mishra, and E. Weber (eds.), Mater. Res. Soc. Symp. proc. 241 (1992)

4. Special Issue Low Temperature GaAs Material, J. Elec. Marer. 22 No. 12 (1993)

5. D.C. Look, Thin Solid Fllms 231 (1993) 61

6. D.J. Eaglesham, L.N. Pfeiffer, K.W. West, and D.R. Dykaar, Appl. Phys. Lett. 58 (1991) 65

7. M. Kaminska, Z. Liliental-Weber, E.R. Weber, T. George, J.B. Kortright, F.W. Smith, B.Y. Tsaur, and A.R. Calawa, Appl. Phys. Lett. 54 (1989) 1881

8. A.C. Warren, J.M. Woodall, J.L. Freeout, D. Grischkowsky, D.T. McInturff, M.R. Melloch, and N. Otsuka, Appl. Phys. Lett. 57 (1990)1331

9. J.J. vonBardeleben, M.O. Manasreh, D.C. Look, K.R. Evans, and C.E. Stutz, Phys. Rev. B 45 (1992) 3372

10. D.E. Bliss, W. Walukiewicz, J.W. Ager III. E.E. Haller, K.T. Chan, and S. Tanigawa, J. Appl. Phys. 71 (1992) 1699

11. N. Hozhabri, R.C. Hyer, S.C. Sharma, J.Y. Ma, R. N. Pathak, and K. Alavi, J Vac. Sct. Technol. B 10 (1992) 788

12. D.J. Keeble, M.T. Umlor, P. Asoka-Kumar, K.G. Lynn, and P.W. Cooke, Appl. Phys. Lert. 63 (1993) 87

13. P. Hautojarvi, J. Małkinen, S. Palko, K. Saarinen, C. Corbel, and L. Liszkay, Mater. Sci. and Engineering B22 (1993) 16

14. M.O. Manasreh, D.C. Look, K.R. Evans, and C.E. Stutz, Phys. Rev. B 41 (1990) 10272

15. K.M. Yu and Z. Liliental-Weber, Mater. Res. Soc. Symp. Proc. 241 (1992) 145

16. D.V. Lang and R.A. Logan, Phys. Rev. Lett. 39 (1977) 635 


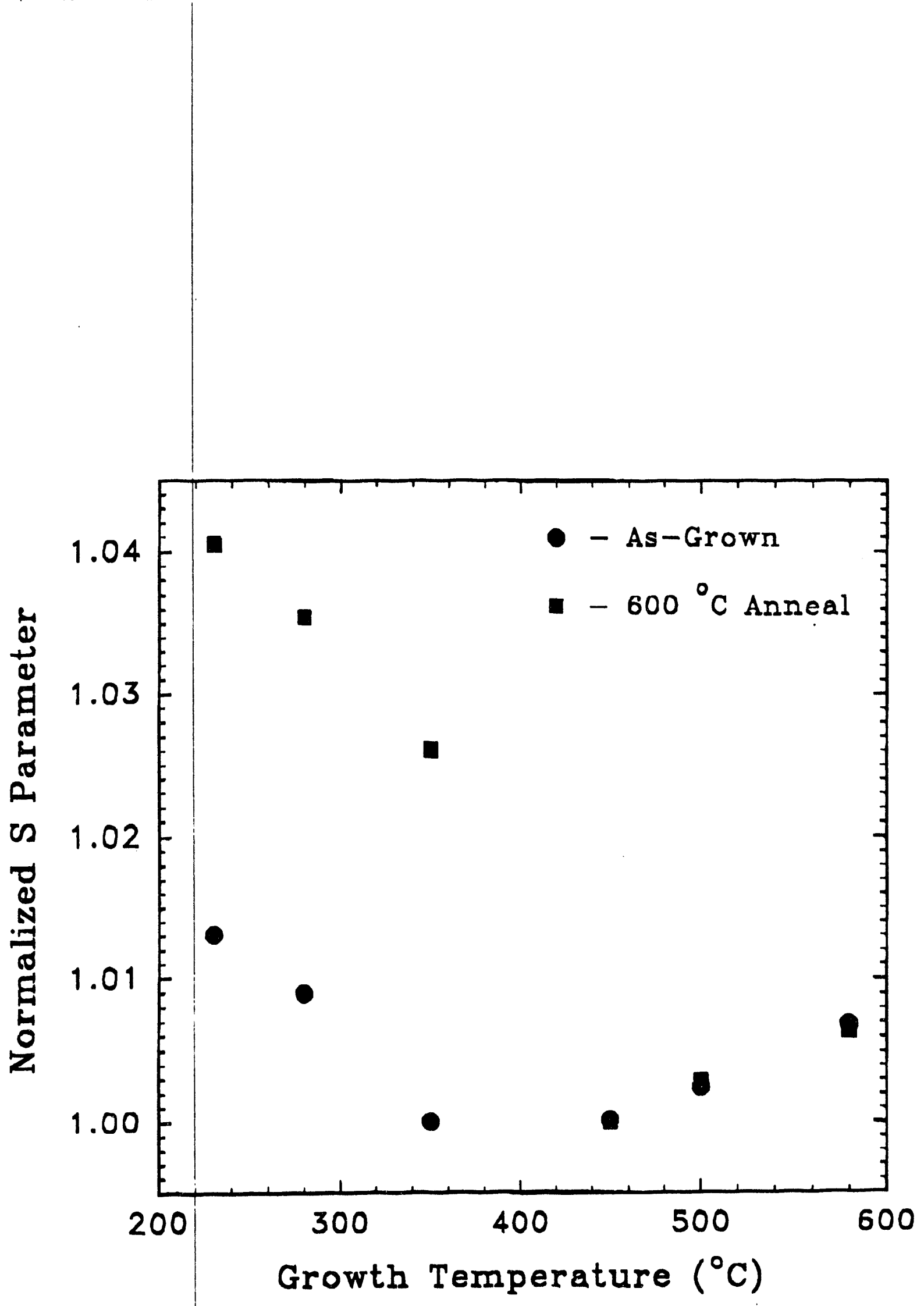


Normalized S Parameter

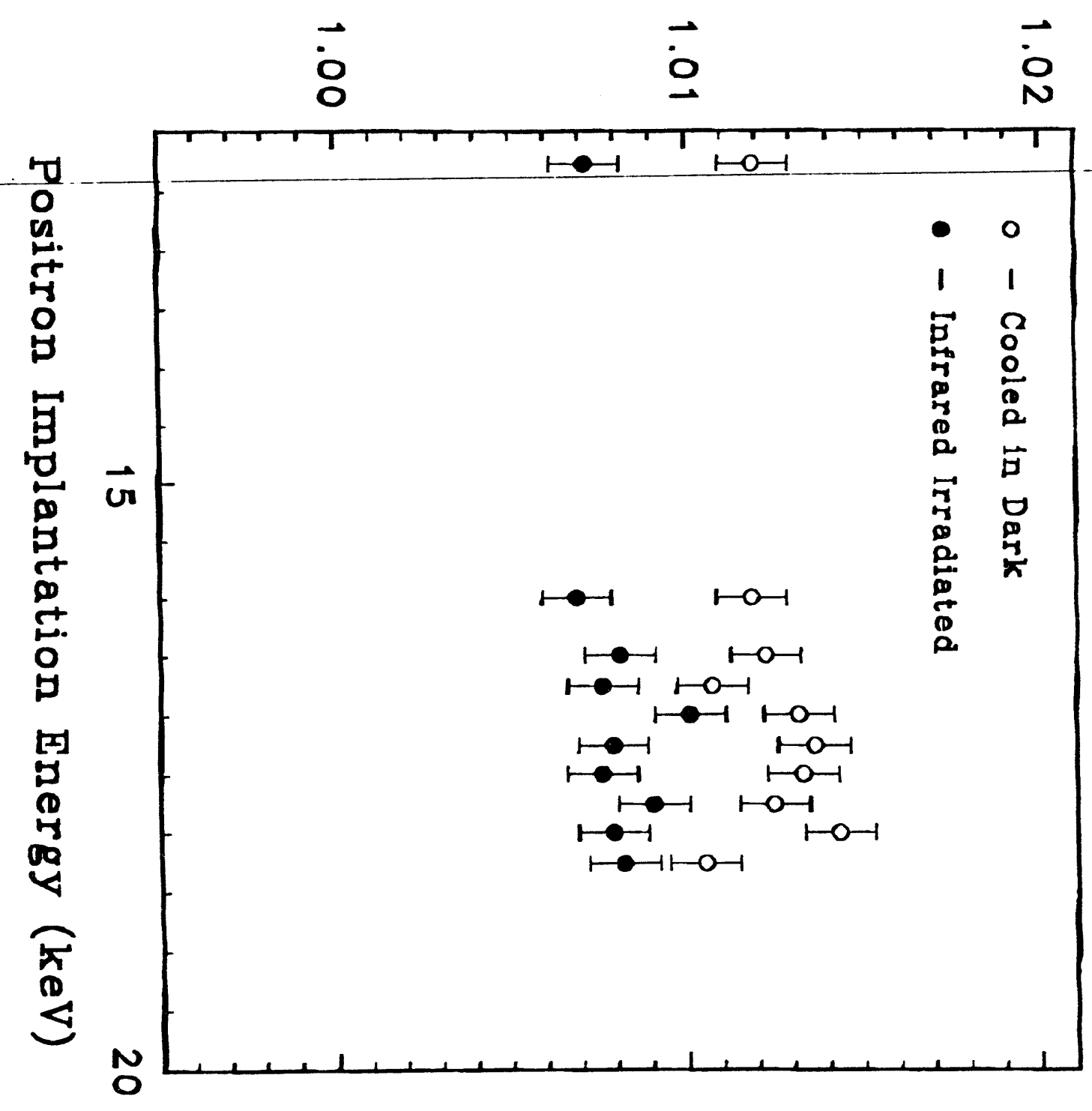



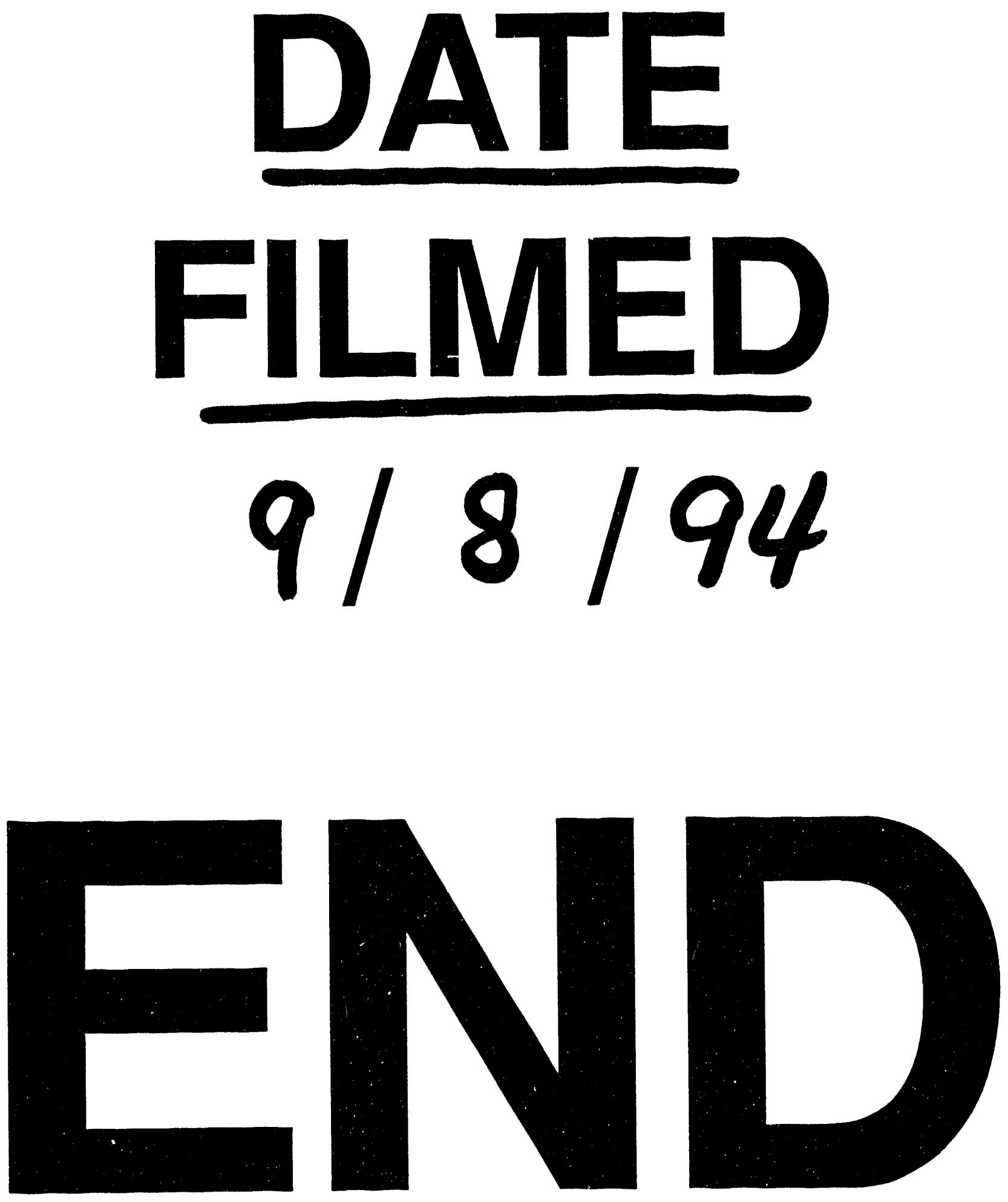
